\title{
Article \\ Minority Youth and Social Transformation in Australia: Identities, Belonging and Cultural Capital
}

\author{
Andrew Jakubowicz ${ }^{1, *}$, Jock Collins ${ }^{1}$, Carol Reid ${ }^{2}$ and Wafa Chafic ${ }^{1}$ \\ ${ }^{1}$ Cosmopolitan Civil Societies Research Centre, University of Technology, Sydney, PO Box 123, Broadway, NSW 2007, \\ Australia; E-Mails: andrew.jakubowicz@uts.edu.au (A.J.), jock.collins@uts.edu.au (J.C.), wafa.chafic@uts.edu.au (W.C.); \\ Tel.: +612-95142298 (A.J.) \\ ${ }^{2}$ School of Education, University of Western Sydney, Locked Bag 1797, Penrith, NSW 2751, Australia; \\ E-Mail: C.Reid@uws.edu.au \\ * Corresponding author
}

Submitted: 6 October 2013 | In Revised Form: 30 April 2014 | Accepted: 1 May 2014 | Published: 20 August 2014

\begin{abstract}
Increasingly minority youth, especially from Muslim backgrounds, have been seen in Australian public policy and the media as potentially disruptive and transgressive. In some European societies similar young people have been portrayed as living in parallel and disconnected social spaces, self-segregated from interaction with the wider community. Yet Australian ethnic minority youth do not fulfil either of these stereotypes. Rather, despite their often regular experiences of racism or discrimination, they continue to assert a strong identification with and belonging to Australian society, albeit the society that marginalizes and denigrates their cultural capital. In particular it is the neighbourhood and the locality that provides the bridge between their home cultures and the broader world, contributing to a range of positive aspirations and fluid identities.
\end{abstract}

\section{Keywords}

belonging; cultural capital; migrant youth; participation; racism; space

\section{Issue}

This article is part of the special issue "Migrant Youth, Intercultural Relations and the Challenges of Social Inclusion", edited by Professor Fethi Mansouri (Deakin University, Australia) and Dr. Anna Halafoff (Deakin University, Australia).

(C) 2014 by the authors; licensee Cogitatio (Lisbon, Portugal). This article is licensed under a Creative Commons Attribution 4.0 International License (CC BY).

\section{Immigration and Social Transformation: An Introduction}

Since the beginning of this century immigration to Australia has accelerated, accompanied by a major rise in shorter-stay residents such as contract workers and international students. As immigration has once more burgeoned, so the youth component of the immigrant population (born overseas and born locally of overseas born parents) has also expanded (Collins, 2013). This paper asks: what does the expanding presence of minority youth mean for the social transformation of Australian society? As analysts such as Anita Harris (2010) have argued, public policy is increasingly perturbed by the apparent growing marginalisation of minority youth from mainstream culture, yet the public conversation about these concerns fails to recognise either the super-globalisation that has transformed national boundaries, or the densification of diasporic communities that globalisation has thus enabled. Our research on minority youth reported and discussed in this paper, explores to what extent minority youth are indeed "marginalised", and what the implications may be of their relationship to questions of identity and belonging. We ask whether the social transformations that are discernable are producing marginalisation, and if 
they are, are these tensions productive of positive social transformations leading to new forms of inclusion and belonging, even if they are no longer codified in some archaic, unitary and undifferentiated idea of the nation?

We begin by setting the context, then we explore what we mean by social transformation, and then we proceed to identify and investigate the place of minority youth in the processes we examine. Finally we assess the implications for public policy of the situations we report.

Australia has been a society formed by immigration since its first invasion and settlement by Europeans in the late eighteenth century, so that much of its history has been concerned with government control over the makeup of its population. Australia had a culturally diverse population in the nineteenth century; the original Indigenous population encompassed many hundreds of nations, while the gold rushes in particular drew tens of thousands of fortune-seekers including significant numbers of Chinese and other Asians. Much of this non-European immigrant diversity was stalled by the White Australia immigration restriction policies introduced after Federation in 1901, while Indigenous populations also fell under the impact of introduced diseases, frontier violence and the loss of land. For three generations after the foundation of the Commonwealth, national policy focussed on building a population by excluding "non-White" immigration and expelling non-White settlers, while assimilating the surviving Indigenous peoples. After World War II, national policy expanded its search for immigrants to non-British parts of Europe, while retaining barriers to non-White entry. In a short period from the mid-1960s to the mid-1970s however, governments of both conservative and Labor orientation opened up immigration to new populations from across the world (Jakubowicz, 2009).

From about 1970 onwards migration included new intakes of Muslims in what had been in the past an overwhelming European Christian immigration intake; it also began to include significant numbers of both Christians and non-Christians from Indo-China and China, and from the Middle East. Later it would also draw in people from many African countries, both Christian and Muslim, so that by Census Day 2011 Australia was no longer recognisable in its ethno-cultural diversity as the country it had been two generations before (DIAC 2013; Ho \& Jakubowicz, 2013). Importantly the diversity of Australian society means that the huge concentrations of particular immigrant groups in specific localities that characterise many European countries and have been linked to the "failure of multiculturalism" (Jakubowicz, 2013; Meer \& Modood, 2011; Modood, 2012) are not part of the Australian urban scene. Nevertheless long-entrenched structures of racial exclusion and hierarchies continue, especially in some areas of major cities, driven in part by regular moral panics over threats to the social order that these immigrants and their children might represent (Dunn, Klocker, \& Salabay, 2007; Markus, 2014).

These increasingly diverse diaspora communities are one of the local consequences of well-recognised global processes of "social transformation", especially those accelerated by neo-liberal economic development on the one hand, and major local conflicts in source countries on the other (Castles, de Hass, \& Miller, 2014). Today the newest waves of arrivals enter Australia in very different circumstances and encounter a very different economic dynamic to those that greeted the first generation of post-White Australia immigration after the 1970s (Collins, 1991; Jakubowicz, 2009). The social transformation now underway in Australia plays a key role in generating the opportunities and constraints that young people from newer immigrant groups experience, often in ways not previously considered by public policy. Specifically the neo-liberal driver behind social transformation (Castles, de Haas, \& Miller, 2014) appears to generate specific challenges for minority youth in relation to their familial and socially-acquired cultural capital (Shah, Dwyer, \& Modood, 2010) including its value to them for gaining access to the wider opportunities of a multicultural society such as Australia.

Four factors are important in positioning the debate about immigrant youth in contemporary Australia. Given that our interest is in how youth from immigrant communities perceive and are perceived by Australian society, we wish to outline these factors and then explore how they interrelate.

First the economic restructuring that has characterised the decades after 1983 with the floating of the Australian dollar, deregulation of finance and reduction of tariff protection, has further integrated Australia's economy into that of the wider region and internationally. As a consequence many industries that sought to recruit lower skilled migrant labour in the past, have now either heavily upgraded the technologies they use and thus the skill base of the workforce they require, or have failed and closed in increasingly competitive business environments (as has the motor vehicle manufacturing industry over 2013 and 2014) (Collins, 2013). For immigrant families, especially those with a fairly low skill base (including some refugee communities) (Refugee Council of Australia, 2011) the loss of employment by the first "father" and "mother" generation has seriously disrupted family life (Colic-Peisker \& Tilbury, 2007). Lack of employment opportunity has become an increasingly vital factor in the public activities of "second (or even third) generation" youth, feeding drivers that push some young people into the informal or "black" economy (Abdelkerim \& Grace, 2012). Education institutions have become front-line agencies in managing the impact of this changing political economy on the life chances and public attitudes of young people (Liddy, 2012). 
Second, cities such as Sydney, Perth and Melbourne have become geographically segmented, where some localities can draw on industries that are more closely tied to the economic opportunities of an increasing globalised market, while others are more locally constrained, offering fewer possibilities for growth. Moreover in these cities three in five of people are either first or second-generation immigrants (born overseas or parent born overseas); overall some 43 per cent of Australia's population is "immigrant" in that sense (Ho \& Jakubowicz, 2013). Yet unlike many European cities most neighbourhoods in Australia's cities are diverse rather than monocultural; it is difficult therefore to speak of them as "ethnic ghettoes" specific to any particular ethnic or immigrant group. It is exactly the diversity of locality, however, that makes attitudes to the local area among young second generation women and men such a useful barometer of their identification with Australian society more broadly.

Third as globalisation has provided increasing opportunities for travel to homeland societies, and technology has opened up instantaneous communication between homelands and Australia, the time space barriers that used to press so heavily on earlier generations of immigrants in relation to sustaining diasporic links have effectively been relegated to history. Globalisation has therefore greatly problematized the 'national' in Australia, enabling diasporic identities to be easily accessed and sustained (Collins et al., 2012). For youth from minority immigrant communities (shorthanded here as "minority youth") their sense of personal status and identity has to continually negotiate their changing perceptions of their parental homeland societies and culture, their own identification with Australia, and their perception of how they are perceived in Australia by others from outside their communities. Identity is thus a contingent process (Colic-Peisker \& Walker, 2003) rather than a fixed state, and its expression can vary considerably, responding to personal, communal, societal and global conflicts (McLeod \& Yates, 1999).

Fourth, the cultural capital of minority youth has become an increasing controversial framework for analysis of their experiences (Jakubowicz, 2011). The use of cultural (Wimmer, 2007) and social capital (Bourdieu, 1986; Bassani, 2007) as conceptual lenses through which the aspirations and experiences of immigrant youth can be interpreted has become an important avenue for research. Schaefer-McDaniel (2004) in her review of social capital has argued that for youth three dimensions are crucial: their social networks, interactions and sociability; their levels of trusts and reciprocity in peer and community relations; and their sense of belonging and attachment to place (as discussed by Hill \& Bessant, 1999). Modood and his colleagues in the UK (Shah, Dwyer, \& Modood, 2010) have taken the concept of cultural capital, as initially proposed by Bour- dieu (2010), and argued that cultural capital should not be separated from its close links to socioeconomic class factors and personal economic capital. Even so, they suggest that class per se does not provide a sufficient framework for analysis without the insights provided through a more anthropological and political inflection drawn from specific cultural analyses. Thus their elaboration of "ethnic (cultural and social) capital" helpfully extends how we might explore and interpret the lived experiences of immigrant youth, within the framework of structural constraints and cultural hierarchies that they encounter in a multicultural society like Australia-with its continuing racialised patterns of advantage and disadvantage. A tension has been identified between in-group focussed "bonding" social capital, and other-group linking "bridging" social capital in diverse multicultural neighbourhoods. Diversity, it has been argued (e.g., Putnam, 2002) reduces inter-ethnic trust, tending to reinforce bonding relationships at the expense of bridging, potentially fragmenting localities into pockets of bonded monocultures that interact but do not integrate. These worries can be key contributors to moral panics over the local presence of minority youth.

\section{Who Are Immigrant Youth?}

The most recent Australian Census (Australian Bureau of Statistics, 2011) demonstrates the rapidly changing makeup of immigrant minority youth. For our purposes we are setting the parameters of this group by their regions of birth, their non-European origins, and the presence among them of significant Muslim groups. These parameters derive from their fairly low position on an ethnic ladder of status that places EuropeanAustralians at the top, and non-Europeans further down the list. The hierarchy is compounded by class factors, partly reflected in the occupations of their parents, and partly for older youth, in their own occupations or lack of them. Intergenerational social mobility, a key goal of many migrants, further confuses the ethnicity/class interaction (Redmond, Wong, Bradbury, \& Katz, 2014). Finally, while religious identity is not a defining characteristic of minority status, and does not point to class position or to educational attainment, the stereotyping of Muslims has been one of the more controversial aspects of their marginalisation in public discourse. In addition to the overseas born, minority youth also encompasses many young people born in Australia of immigrant parents, who fit the concept of "visible minority". The continuity between Australian born and immigrant lies most often in their shared experiences of racism, discrimination and disadvantage (Collins et al., 2012).

In a population of 21.5 million, there were 1.4 million young people aged 15-19, and 1.46 million aged 20 to 24 at the 2011 Census. Together they comprise 
some 13 per cent of the population. Young people born outside Australia made up 13 per cent of 15-19 year olds, and 22 per cent of 20-24 year olds. Non-Europeans made up some 115,000 of the 15-19 year olds (about $2 / 3$ of the overseas born), and about 265,000 of the 20-24 year olds (some 77 per cent of the overseas born). The largest overseas born groups are those from North and East Asia (about 24 per cent), South East Asia (20 per cent), Oceania (17 per cent) South and Central Asia (16 per cent), North West Europe (14 per cent), Sub Saharan Africa (7.5 per cent) and North Afri$\mathrm{ca}$ and the Middle East ( 6.7 per cent). Of those born overseas the largest group (35 per cent) comes from South and Central Asia (especially Pakistan and Afghanistan), then North Africa and the Middle East (30 per cent) (especially Somalia, Lebanon and Iraq), followed by South East Asia (11 per cent) and sub-Saharan Africa (8 per cent). Muslim youth make up about 3 per cent of the whole youth cohort in Australia, perhaps surprisingly low given the level of critical attention focused on young Muslims, especially males. Muslim young people born in Australia represent the single largest country of origin (45\%), and are increasingly of Australian-born parents. As indicated by the Census (ABS, 2011) however, the cultural diversity among Muslims is great, with over 60 different national origins identifiable.

\section{What Our Research Reveals About Immigrant Youth: Key Parameters}

We turn now to examine how these four parameters are extended when applied to two commissioned research projects on immigrant youth. Our projects were initiated by government bodies during the period of a national Labor Government between 2007 and 2011, and were carried out for the federal bureaucracy of the Department of Immigration and Citizenship. In each case the research was framed by a wider public debate, each with their own element of moral panic, about the integration of immigrant youth, their identification with Australian social values as expressed by key elites and reinforced in the media, and concerns expressed by the communities from which they came about stereotyping, marginalisation and social exclusion (Dunn, Klocker, \& Salabay, 2007).

The first survey was of 340 youth -144 males and 195 females-aged from 14 to 17 years living in Western and South-Western Sydney (Collins, Reid, Fabiansson, \& Healey, 2010). Stratified sampling was employed to ensure that at least 80 per cent of respondents were first or second generation male or female youth from a wide range of minority backgrounds, with minority defined as being of a culturally and linguistically diverse background (CALD). We refer to this as the 2007 CALD study ("CY"). The majority of youth surveyed -75 per cent of males and 61 per cent of females-were second generation immigrants that is, born in Australia but with one or both parents born overseas. The largest group of mothers was born in Tonga (25.6 per cent) followed by Korea (11.2 per cent), Lebanon (10.8 per cent) and Sudan (10.5 per cent). The largest group of fathers was also was born in Tonga (24.5 per cent), followed by Korea (11.3 per cent) Sudan (10.9 per cent) and Lebanon (10.6 per cent). Others were born in New Zealand, Sri Lanka, India, China and England. Only 4.3 per cent of the mothers and 4.4 per cent of the fathers were born in Australia.

The second survey of 332 young male and female Muslim Australians conducted at the Muslim Eid Festival and Fair in Sydney in 2010. This survey differed from the one above in that it also included informants aged 15 to 25: 165 informants were aged under 18 and 167 aged between 18 and 25 . We refer to this as the 2010 Muslim Youth study (" $M Y^{\prime \prime}$ ). Like $C Y$, the majority (73 per cent of the respondents aged 15-25 years) were second generation immigrants born in Australia. First generation informants were mostly born in Iraq, Pakistan and Lebanon, although respondents were also drawn from another 26 birthplaces reflecting the great diversity of the Australian Muslim community. The overwhelming majority (94 per cent) of respondents were Australian citizens.

The methodology employed for both surveys drew on a multi-entry snowball sample, rather than a random sample. This method allowed us to use preexisting networks of trusted relationships. These two surveys provide some insight into immigrant youth in contemporary Australian society in general, and into aspects related to their social capital and social relationships and their subjective take on matters related to identities and belonging in particular. The four parameters allowed an examination of how different elements of the lives of our research subjects were interconnected.

\section{Employment Opportunities}

Conservative and Labor Governments in Australia have enthusiastically embraced the globalisation agendas of deregulation of finance, reduction of tariff levels and the privatisation of public sector assets and institutions. This has had a profound impact on the Australian economy in general, and the Australian labour market in particular, with secondary industries like manufacturing continuing to decline as tariff protection has been reduced or eliminated, while services sector jobs continue to increase. At the same time Australian immigration policy has been fine-tuned to embrace the globalisation agenda (Collins, 2013; Jakubowicz, 2013). There are a number of interrelated developments. Immigration intakes have reached record levels, despite the Global Finance Crisis (Collins, 2008). While the UK and New Zealand remain the major source countries for Australian immigration, intakes from Asia, Africa 
and the Middle East have increased considerably in the past decade while skilled and highly qualified permanent and temporary immigrants are prioritized over permanent family and humanitarian entrants, though most skilled immigrants bring family dependents with them. A significant proportion of those arriving in Australia under the Refugee and Humanitarian Program are young people, with 59 per cent of new entrants arriving in the five years between July 2005 and June 2010 aged under 25 years on arrival, and 31 per cent aged between 12 and 25 (Refugee Council of Australia, 2011).

Employment is a key factor in successful immigrant settlement and on the socioeconomic outcomes for first and second generation immigrants, including those whose parents arrived in Australia some decades ago. Employment opportunities for minority immigrants, including young people, have been shaped by the restructuring of the Australian economy that has accompanied globalisation. Changing patterns of labour market segmentation in Australia show that CALD immigrants with tertiary education and skills in the services sector tend to get good jobs and incomes while other CALD immigrants with lower levels of educational achievement-including many Muslim immigrantsare concentrated in jobs in the declining manufacturing sector or lower level jobs in the services sector (Foroutan, 2008). On average, unemployment rates for immigrants are only slightly higher than non-immigrants (Australian Productivity Commission, 2006), although immigrant minorities experienced larger increases in unemployment in the economic downturn following the Global Financial Crisis (Hugo, 2011b; Collins, 2011). But averages conceal a variety of different immigrant labour market experiences for CALD immigrants. More disaggregated analysis by ancestry (a proxy for ethnicity), generation, religion or by category of immigrant entry reveals significant variation about the mean in terms of unemployment rates for immigrants. For example, 2006 Australian Census data reveals that first and second generation immigrants of Lebanese/Middle Eastern ancestry, or Vietnamese and North African ancestry, had rates of unemployment two-to-three times higher than average. Twenty-two per cent of the Vietnamese second generation and 15 per cent of the North African/Middle East second generation were unemployed at a time when the Australian economy was generally regarded as fully employed with average national unemployment rates between 5-6 per cent (Collins, 2011). Muslim immigrants also suffer significantly higher unemployment rates than others, with prejudice and discrimination as key factors (Lovatt et al., 2011). Refugees are the most disadvantaged cohort of immigrant arrivals and face the greatest settlement difficulties in Australia: one-third of refugee-humanitarian entrant settlers remain unemployed after three years of settlement in Australia (Hugo, 2011a, p. 104). Moreover a 2014 study of locality-linked youth employment demonstrated that youth unemployment in regions of high minority residence could be as much as three times as high as the national average, and twice as high as youth unemployment in general (though lower than rural rates). Discussing the implications of global economic restructuring the Report argued that "the global financial crisis has had a scarring impact on the job prospects of Australia's young people" (Brotherhood of St Laurence, 2014; Kwek, 2013).

Educational outcomes for CALD immigrant youth are also uneven. Youth from families of professional and highly skilled immigrant parents - such as skilled immigrants from China and India and Korea, the largest countries of skilled CALD immigrant arrivals-have strong educational achievement in Australian schools. On the other hand, first generation youth from families where the parents have lower educational qualifications and second generation youth whose parents arrived in earlier decades when there was less priority given to skilled immigration intakes have relatively poor educational outcomes in Australian schools (Redmond et al., 2014). This uneven educational performance of CALD youth in Australia reinforces the patterns of labour market segmentation and the uneven labour market outcomes of CALD youth. Young people from refugee families have relatively poor employment and educational outcomes compared to other CALD youth and to Australian youth as a whole (Abdelkerim \& Grace, 2012).

Minority youth bear many of the costs of Australia's globalisation and neo-liberal economic agendas. As such employment opportunities decline, higher levels of more technically advanced skills are required, and school and other public education systems suffer under government funding cuts, and there is a "flight" of middle class children to private (fee-paying) schools associated with religious or cultural communities (Redmond et al., 2014).

\section{Urban Segregation}

Most Australian immigrants settle in the large Australian cities of Sydney, Melbourne, Perth, Brisbane and Adelaide (Hugo, 2011b; Hugo, Feist, \& Tan, 2013). But immigrant settlement is not evenly distributed within these cities, particularly for CALD immigrant minorities. This is particularly evident in Sydney and Melbourne, Australia's largest cities where over half of all Australia's immigrants settle. CALD immigrants are concentrated in the western and south-western suburbs of Sydney and the western suburbs of Melbourne; however specific ethnicities never approach a majority of the immigrant population (Islam is not classed as an ethnicity, but rather as a faith community).

Not surprisingly then Muslim immigrants also concentrate in these areas. According to the 2006 Census nearly half (47.3 per cent) of Muslims in Australian 
lived in Sydney, while just under a third (30.3 per cent) lived in Melbourne (DIAC, 2007, p. 6). By 2006 seven out of the top ten Australian suburbs of Muslim immigrant settlement were in Western and South-Western Sydney: Auburn, in Sydney's western suburbs, was the most Muslim Australian suburb, with 24.8 per cent of the population reporting that Islam was their religion, followed by Bankstown (15.2 per cent) and Canterbury (13.7 per cent) (DIAC, 2007, p. 7). Patterns of immigrant settlement are changing as newly-arrived professional and tertiary educated immigrants move to wealthier suburbs, such as Chatswood in Sydney's North Shore for Chinese immigrants and inner northwest suburbs of Strathfield and Eastwood for the Sydney Korean population. At the 2013 election the ten federal electorates with the highest proportion of Muslims were in western Sydney or Melbourne, and the top five Vietnamese seats were in the same areas; they were all held by the Labor Party until the election. The Chinese population was more dispersed across geography and evinced a wider partisan representation (Mumble Census Gallery, 2013).

Urban unemployment rates in Australia reflect the cultural geography of Australian cities. These western suburbs of Sydney and Melbourne are the areas where the manufacturing industry in located, and so exhibit high unemployment rates. For example, in 2013 while Sydney's Northern Beaches and Eastern Suburbs had unemployment rates of 2.1 per cent and 3.2 per cent respectively, Fairfield-Liverpool-perhaps the densest area of minority immigrant settlement in Australiaexperienced an unemployment rate of 7.1 per cent. Similarly, Melbourne's Outer Western area had unemployment rates of 7.1 per cent while in North Western Melbourne the unemployment rate was 9.4 per cent. Broadmeadows, a Melbourne western suburb with a very high CALD and Muslim population, is set to experience much higher unemployment rates as the Australian car industry closes down. Unemployment rates are higher for youth than adults. When viewed through the lens of cultural geography, it is clear that minority youth who live in areas such as western Sydney have very high unemployment rates. In May 2012, for example, when the overall unemployment rate for Western Sydney was 5.5 per cent, for youth it was 17.9 per cent, with youth in Fairfield Liverpool experiencing much higher unemployment (Montoya, 2012). Muslim unemployment rates are more than double the average (Masanauskas, 2012).

Immigrant settlement patterns suggest that while new immigrants concentrate in areas such as the western suburbs of Sydney and Melbourne, immigrant ghettoes do not emerge. As Hugo (2011a, p. 24) put it: "A distinctive characteristic of Australia's largest cities compared with some other world cities, however, is that while there are suburbs with high proportions of foreign-born residents, these concentrations are not dominated by a single birthplace group". This fact has important implications for issues related to the social cohesion of minority youth in Australia and to their sense of belonging. The riots involving immigrant minority youth in the UK (Bradford, Burnley, and Oldham in 2002) and France (Paris in 2005) occurred in places with much greater concentration of immigrant youth from a particular ethnic or religious background (Collins \& Reid, 2009). The Cantel Report (Cantel, 2004) into the Bradford, Burnley, and Oldham riots identified the "depth of polarisation" between white and minority youth in Britain, leading them to live disconnected "parallel lives". Our reports on research with immigrant youth living in the suburbs of Western and South Western Sydney demonstrate that the population is very diverse in terms of ethnic, cultural, religious and social class, cosmopolitan or multicultural rather than monocultural immigrant ghettoes.

\section{Global Versus Local}

As globalisation increases the immigrant youth populations of all western nations, there has been a growing anxiety about the extent that these immigrant youth will identify with the nation and contribute to nationbuilding and social cohesion in coming decades. These concerns about the national identity of immigrants and the extent to which they will buy into and identify with their new nation is not recent phenomena and can be traced to the first years of the post-war Australian immigration program (Kabir, 2008). Yet the recent anxiety about minority immigrant youth-particularly those of Muslim faith-are sharpened in the post-9/11 environment, by the Cronulla beach riot, the Sydney gang rape involving Muslim Lebanese youth, the Bali bombings, the arrest of Muslim men in Sydney and Melbourne for terrorist activities and, more recently, the involvement of Australian youth of Muslim background fighting in the conflict in Syria (Jakubowicz, 2009). These anxieties are generally framed around a homogenized and stereotyped racialised construction of minority immigrant cultures and the Muslim religion as being anti-Western, criminal and hostile to and separate from-rather than integrated into and contributing to building-the Australian nation (Kabir, 2008). Given the limitations of social mobility pathways (e.g. well-paying jobs with promotional prospects) for some immigrant minority youth, their integration rather than their marginalisation and exclusion into Australian society in part depends on how their identities are validated as stakeholders in the society.

As Tabar, Noble and Poynting (2003) point out in their research on Australians of a Lebanese background, "identities are not simply symbolic entities through which we represent ourselves and others, but embodies practices of identification and adaptation deploying particular kinds of resources which we position ourselves in diverse social domains". The inform- 
ants in the $2007 \mathrm{CY}$ study were asked to describe their national identity. Two thirds of the young people surveyed were born in Australia yet only slightly more than one in three of the respondents identified as "Australian". The rest gave a wide range of identities mostly related to the country of origin of their parents. This supports the argument that minority youth in Sydney have diverse, fluid and multiple identities. Butcher and Thomas (2003) who also interviewed young people in western Sydney, found that they forged hybrid identities that incorporate their migrant identities with elements of "being Australian".

A slightly different but related question about whether the informants in the $2007 \mathrm{CY}$ survey felt Australian all the time, often, sometimes or rarely, found that about half of the respondents "felt Australian" (48.5 per cent) all the time or often. Two in three young people reported to "often feeling good about living in Australia" and another one in four young people reported to "sometimes feeling good about living in Australia" while a fifth of the young people did not really feel "Australian" at all. Despite this finding most (two in three respondents) liked living in their Sydney suburb and felt that they belonged in and had ownership of their local neighbourhoods. On the other hand, one in three males and one in four females "rarely" or "never" felt ownership of their local area.

The youth surveyed demonstrated strong aspirations and a confidence about their future in Australia. Only a few of the youths expressed pessimism about their chances of achieving their preferred occupation in the future. When asked to nominate their most important values, friendship, honesty, trust, family, respect and loyalty were the most frequently mentioned.

The Muslim youth survey (2010 MY) inquired into many of the issues explored in the earlier survey, including subjective assessments of identity and belonging. Most of the young Muslim Australians-82 per cent of young Muslim women and 78 per cent of young Muslim men feeling-felt good about living in Australia. One in three ( 37 per cent) of Muslim youth surveyed self-identified as "Australian" while a similar number (37 per cent) gave their identity as "Australian Muslim". Another one in five (19 per cent) responded that they were of hybrid identity, a combination of Australian with some other ethnicity or nationality. In other words, the vast majority of Muslim youth (93 per cent) surveyed used the identifier "Australian" in part or whole of their identity. When compared to the $2007 \mathrm{CY}$ survey reported above, the youth in the 2010 MY survey was more likely to identify as Australian. One explanation for this may be that the experience of the Sydney Cronulla beach riots of December 2005 resonated more in the 2007 survey than the 2010 survey. Another relevant factor to consider is that the Muslim youth survey also included those aged between 18-25 years. Even so, Muslim youth continue then to identify as Australian, belying the fear expressed by some that non-Christian immigrant youth represent a threat to Australian social cohesion (Kabir, 2008).

\section{Cultural and Social Capital}

A key aspect of minority immigrant youth integration relates to the extent to which they are socially included in their neighbourhood and, by extension, their nation. In the UK the Cantel Report suggested that immigrant youth were disconnected from other British youth: they lived parallel rather than interrelated lives. At a neighbourhood level the social relations between minority immigrant youth and others and their level of social interconnectedness and trust with other youth and adults is thus an important area of investigation. The two Sydney surveys canvassed responses to a wide range of questions designed to gain information about the lives of these immigrant youth, their friendship networks, values, aspirations, identities and belonging. In the 2007 CALD youth survey most young people surveyed reported that they had multicultural social networks and lived lives connected to youth of other ethnic, cultural or religious background. The survey provides strong evidence that social cohesion represents the norm for inter-ethnic youth relations in Sydney's western and south-western suburbs. The young people who identified as "Anglo" - the largest group in the sample-stated that in descending order their friends came from Australia (the majority), followed by Tonga, Lebanon, parts of Asia , as well as China and Korea. The second largest group was from New Zealand. The majority of their friends were Tongan, Asian and Islander. The Sudanese had the majority of their friends among Australians and among other Sudanese, but also among the Lebanese and Indian youth.

The 2010 MY survey also explored the friendship networks of Muslim youth in Sydney. The vast majority (80 per cent) of respondents reported that they had non-Muslim friends. Only 16 per cent of the youth surveyed had only Muslim friends, with Muslim youth aged under 18 twice as likely to report that all of their friends are Muslim as Muslim youth aged over 18. On the other hand, two in three (64 per cent) surveyed reported that most of their friends were Muslim, while 16 per cent reported that some of their friends were Muslim. Finally, questions about the values and beliefs that the Muslim youth held to be important were asked. Two in three replied that honesty and religious practices were most important. More than half of the respondents also listed responsibility, tolerance and respect for other people, politeness and neatness and patience as key values of the Muslim home. Other important values were hard work, independence, obedience, leadership and imagination. Clearly these are values that are consistent with "Australian values", and they challenge arguments that present Islam as a 
threat to the Australian way of life.

Discrimination is an issue of key concern to Australia's Muslim communities' post 9/11. We thus asked the Muslim youth surveyed about their experiences of discrimination at school and in the public domain. Just over one half of respondents (55 per cent) had never experienced discrimination at school, while 11 per cent reported one incidence of discrimination. 30 per cent reported that they had experienced discrimination a few times and 4 per cent reported that they had experienced discrimination often. While two in three Muslim youth who attend Muslim schools had never experienced discrimination at school, one in two who attended non-Muslim schools had never experienced discrimination at school. Experiences of discrimination at school increased with the age of the respondent. This issue was not explored in the 2007 survey.

Muslim youth experiences of discrimination in the public domain were also explored. Only a minority of respondents (28 per cent) reported that they had never experienced discrimination in public. Most of those Muslim youth surveyed reported experiencing discrimination once (19 per cent) or a few times (45 per cent). When the gender dimension is explored, slightly more young Muslim women reported experiencing discrimination in public, than young Muslim men, though gender differences do not appear to be significantly different in this regards. Responses to women who wear the hijab are a key factor here.

\section{Marginalisation, Inclusion, Transformation and Public Policy}

While immigrant youth make up about one in five of the youth population, in parts of Australian cities where their communities are concentrated, seven in ten of overseas born youth are not of European origin. Two in five of North African and Middle East youth, and a quarter of South and Central Asian youth are Muslim (ABS, 2011). Thus in a comparatively short period, working class urban minority youth, once thought of as being predominantly from southern European origins, are now far more likely to have African, Middle Eastern or South Asian cultural backgrounds. On the other hand, urban minority youth also increasingly come from middle class and professional immigrant families of Chinese, Korean or Indian cultural backgrounds (Collins, 2013). What then are the implications of our research about their identities and experiences for both scholarly questions about approaches to analysing "minority"/"majority" relations, and policy questions about appropriate strategies for government and civil society programs?

We have argued that the public moral panic over identification and participation of minority youth obscures four more deeply rooted factors, namely:

- rapidly changing economic circumstances and the impact of these changes on labour market demand and skill availability;

- geographical segregation and the differentiation in opportunity that such segregation intensifies;

- enlivening of diasporic linkages to countries of origin through the ease of communication and travel together undermining the "tyranny of distance"; and

- widely divergent assessments of the value of the cultural and social capital minority youth inherit, reproduce and create.

In a multicultural society there can be no single "culture"; but rather a complex intertwining of cultural fragments "sewn together" from time- and place-inflected life ecologies. These fragments, of different weights, draw in dominant culture expectations and resources, ethnocultural familial experiences, intergenerational peer group cultures, and global youth cultural ideas and desires. On reflection, these fragments are integrated into personal narratives that call up a hybrid identity, in which young people talk about the situational and contextual bases for expressing one aspect of their identity over others.

Given the changing economic context, overlaid with cultural power hierarchies and public discourses that regularly problematize the presence of minority youth, one of the most important parameters of social transformation will be the possibilities associated with stable, satisfying and reasonably-remunerated employment. We can see in the current recalibration of labour markets, that younger people with limited or inflexible labour market skills will experience greater difficulty in securing work. Compounded by discrimination in the labour market and stigmatisation in the discourses of the wider media, finding worthwhile job opportunities presents its own set of very real challenges.

The cultural geography of Australian cities has not created the mono- or bi-cultural urban enclaves that produced the "parallel lives" of minority youth in Britain. The multicultural neighbourhoods of Australian cities allow for more cosmopolitan international and friendship networks to develop. Nevertheless evidence persists of the reinforcing processes of marginalisation, in which racism plays a rather too important role. Our research shows that minority youth do identify with their neighbourhoods and localities, feeling that they have a stake in the local turf, yet a minority are less comfortable even in the spaces in which they live compared with young people of Australian majority heritage.

Possibly the most challenging aspect of the social transformations in which minority youth are entwined relate to their sense of personal value and worth. Given that identity builds through praxis, that is to say the performance and production of self in a complex and resistant world, every component plays a contributing role. Minority youth draw on cultural capital that they 
possess (from the sources discussed above) and in the process utilise and contribute to the building of social capital. It is apparent from the findings that there is evidence for "bridging social capital", and that "bonding social capital" is quite well developed in comparison to relations they have into wider institutions and across into other social groups. This is not unusual for minority immigrant communities experiencing significant levels of discrimination, racism and various forms of inequity. Their capacity to enter into wider social and economic relations will therefore depend heavily on the success they have in gaining educational and training qualifications. The minority of minority youth who do not succeed in the educational system (and the majority clearly are able to gain social mobility in the generation after their parents' arrival) are confronted by labour markets far less interested in unskilled school leavers.

The public policy implications of this research also require us to link together the four critical components. Social inclusion will depend on awareness and careful appreciation of local economic environments and the sorts of skills that are increasingly required. Urban regional employment and educational intelligence strategies across three levels of government, incorporating civil society and business organisations should plan to integrate technology and employment forecasting, with flexible forms of educational delivery at school, in technical and further education (TAFE), and in more specialised professional areas. Unfortunately national policy priorities have moved away from concerns that would directly address the employment/social inclusion nexus (the Coalition government has abandoned the former government's social inclusion strategy and the Board that managed it, while state governments are reducing funding to the TAFE sectors in New South Wales and Victoria). Moreover the national government has argued that the market should determine the survival of businesses, and those that are not viable in a free market should be permitted to disintegrate. The most significant concentrations of most vulnerable minority youth live in regions where "old industry" is most prevalent, and they are therefore most likely to experience the closure of industries that in the past offered significant employment to their parents and elder siblings. Industry redeployment strategies should therefore include those "not yet" in the workforce as an element in any equation.

Even though Australia is a multicultural society, many public narratives of contemporary life tend to portray minority youth as antagonistic to the core values of society. Yet our findings demonstrate that on many counts minority youth hold very strongly to what might be seen as core Australian values, especially values associated with more conservative faith communities. Moreover, they have strong aspirations and see a very strong and positive future for themselves in Australia in the coming decades.
While the public policy implications require more attention than can be given here, two cultural policy trajectories need to be reinforced. First sustained work is needed with the media by government and civil society to reduce the negative and stereotypical representation of minorities as threats or victims. The media will need to take greater responsibility for opening opportunities for the representation of and participation of minority youth as the subjects in their own and wider Australian narratives, from advertising to drama, from news and current affairs, to comedy and melodrama. Where this proves effective it can increase the confidence and therefore the participation of minority youth, while also reducing the apprehension expressed by older Australian communities about newer and unfamiliar arrivals. There is also a clear need to strengthen anti-racist discrimination institutions, policies and practices in Australia, though the current trend is strongly in the opposite direction.

Finally a wider societal conversation needs to emerge that can discuss what it means to have a multicultural society that reduces the salience of ethnicity as a barrier to mobility and participation, while supporting the development of cultural expressions that bridge between Australia's many cultural communities, however "novel" they may appear to "old Australia". The social transformations sweeping through Australia as a consequence of global, national and regional changes will carry serious consequences for cohesion and inclusion. Recognition of the dangers and the identification of the opportunities may ensure that their impact leads to greater future economic prosperity, mobility and socio-cultural integration.

\section{Acknowledgements}

We would like to thank our colleagues at the Cosmopolitan Civil Societies Research Centre at the University of Technology, Sydney, who participated in the Muslim youth "Voices" project. We particularly thank the anonymous referees whose careful response to our paper has improved it dramatically.

\section{Conflict of Interests}

The authors declare no conflict of interests.

\section{References}

Abdelkerim, A. A., \& Grace, M. (2012). Challenges to employment in newly emerging African communities in Australia: A review of the literature. Australian Social Work, 65(1), 104-119.

Australian Bureau of Statistics. (2011). Census of Population and Housing. Canberra: Australian Bureau of Statistics. Retrieved from: http::www.abs.gov.au/ census 
Australian Productivity Commission. (2006). Economic Impacts of Migration and Population Growth, Final Report. Canberra: Australian Government Productivity Commission.

Bassani, C. (2007). Five dimensions of social capital theory as they pertain to youth studies. Journal of Youth Studies, 10(1), 17-34.

Bourdieu, P. (1986). The Forms of Capital. In J. Richardson (Ed.), Handbook of Theory of Research for the Sociology of Education (pp. 241-258). New York: Greenword Press.

Bourdieu, P. (2010). Migrating cultural capital: Bourdieu in migration studies. Sociology, 44, 642-660.

Brotherhood of St Laurence. (2014). Australian Youth Unemployment 2014: Snapshot. Retrieved from: http://www.bsl.org.au/pdfs/MyChanceOurFuture_ Youth_unemployment_snapshot_Feb2014.pdf

Butcher, M., \& Thomas, M. (2003). Ingenious: Emerging Youth Cultures in Urban Australia. Sydney: Pluto.

Cantel, T. (2004). The End of Parallel Lives? The Report of the Community Cohesion Panel. London: Home Office.

Castles, S., de Haas, H., \& Miller, M. (2014). The Age of Migration: International Population Movements in the Modern World (5th ed.). London: Macmillan.

Colic-Peisker, V., \& Walker, I. (2003). Human capital, acculturation and social identity: Bosnian refugees in Australia. Journal of Community and Applied Social Psychology, 13(5), 337-360.

Colic-Peisker, V., \& Tilbury, F. (2007). Integration into the Australian Labour Market: The Experience of three "visibly different" groups of recently arrived refugees. International Migration, 45(1), 59-85.

Collins, J. (1991). Migrant Hands in a Distant Land: Australia's Post-War Immigration. Sydney and London: Pluto Press.

Collins, J. (2008). Globalisation, immigration and the second long post-war boom in Australia. Journal of Australian Political Economy, 61(June), 244-266.

Collins, J. (2011). The Global Financial Crisis, Immigration and Immigrant Unemployment, and Social Inclusion in Australia. In J. Higley, J. Nieuwenhuysen, \& S. Neerup (Eds.), Immigration and The Financial Crisis: The United States and Australia Compared (pp. 145-158). Cheltenham, UK: Edward Elgar Publishing.

Collins, J. (2013). Multiculturalism and immigrant integration in Australia. Canadian Ethnic Studies, 45(3), 133-149.

Collins, J., \& Reid, C. (2009). Minority youth, crime, conflict and belonging in Australia. Journal of International Migration and Integration, 10(4), 377-391.

Collins, J., Reid, C., Fabiansson, C., \& Healey, L. (2010). Tapping the Pulse of Youth in Cosmopolitan SouthWestern and Western Sydney: A Pilot Study 2007. A Research Project under the Department of Immigration and Citizenship's National Action. Retrieved from http://www.immi.gov.au/media/publications/ multicultural/pdf_doc/tapping-pulse-youth.pdf

Collins, J., Jakubowicz, A., Chafic, W., Al Momani, K., Hussain, J., Ghosh, D., Cole, D., \& Pennycook, A. (2012). Voices Shaping the Perspectives of Young Muslim Australians. Department of Immigration and Citizenship. Retrieved from http://www.immi. gov.au/media/publications/research

DIAC. (2007). Muslims in Australia: Based on the 2006 Census of Population and Housing, Program Statistics and Monitoring Section. Canberra: Department of Immigration and Citizenship.

DIAC. (2013). Australia's Migration Trends 2011-12. Retrieved from http://www.abs.gov.au/ausstats/abs @.nsf/Lookup/2071.0main+features902012-2013

Dunn, K., Klocker, N., \& Salabay, T. (2007). Contemporary racism and Islamophobia in Australia: Racializing religion. Ethnicities, 7(4), 564-589.

Foroutan, Y. (2008). Employment differentials of second-generation Muslim immigrants: Assimilation and discrimination hypotheses. Immigrants \& $\mathrm{Mi}$ norities: Historical Studies in Ethnicity, Migration and Diaspora, 26(3), 219-241.

Harris, A. (2010). Young people, everyday civic life and the limits of social cohesion. Journal of Intercultural Studies, 31(5), 573-589.

Hill, R., \& Bessant, J. (1999). Spaced-out? Young people's agency, resistance and public space. Urban Policy and Research, 17(1), 41-49.

Ho, C. (2103). From Social Justice to Social Cohesion. In A. Jakubowicz \& C. Ho (Eds.), "For Those Who've Come Across the Seas...": Australian Multicultural Theory Policy and Practice (pp. 31-44). Melbourne, Australian Scholarly Publishing.

Ho, C., \& Jakubowicz, A. (2013). The realities of Australian Multiculturalism. In A. Jakubowicz \& C. Ho (Eds.), "For Those Who've Come Across the Seas...": Australian Multicultural Theory Policy and Practice (pp. 314). Melbourne: Australian Scholarly Publishing.

Hugo, G. (2011a). Changing Spatial Patterns of Immigrant Settlement. In M. Clyne \& J. Jupp (Eds.), Multiculturalism and Integration: A Harmonious Relationship (pp. 1-40). Canberra: ANU Press.

Hugo, G. (2011b). International Migration in Australian and the Global Financial Crisis. In J. Higley, J. Nieuwenhuysen, \& S. Neerup (Eds.), Immigration and the Financial Crisis: The United States and Australia Compared (pp. 35-56). Cheltenham, UK: Edward Elgar Publishing.

Hugo, G., Feist, H., \& Tan, G. (2013). International migration and regional Australia. Australian Population and Migration Research Centre Policy Brief, 1(4). Adelaide: University of Adelaide.

Jakubowicz, A. H. (2009). New Groups and Social Cohesion in Australia. In J. Higley, J. Nieuwenhuysen, \& S. Neerup (Eds.), Nations of Immigrants: Australia and the USA Compared. London: Elgar.

Jakubowicz, A. (2011). Playing the triangle: Cosmopoli- 
tanism, Cultural Capital and Social Capital as intersecting scholarly discourses about social inclusion and marginalisation in Australian public policy debates. Cosmopolitan Civil Societies Journal, 3(3), 6891. Retrieved from http://epress.lib.uts.edu.au/ journals/index.php/mcs/article/view/2215/2574

Jakubowicz, A. (2013). Comparing Australian Multiculturalism: The International Dimension. In A. Jakubowicz \& C. Ho (Eds.), "For Those Who've Come Across the Seas...": Australian Multicultural Theory Policy and Practice (pp. 15-30). Melbourne: Australian Scholarly Publishing.

Kabir, N. A. (2008). Are young Muslims adopting Australian values? Australian Journal of Education, 52(3), 229-240.

Kwek, G. (2013). Australia's lowest jobless rate. Sydney Morning Herald, 16 May 2013. Retrieved from http:// www.smh.com.au/business/the-economy/austra lias-lowest-jobless-rate-20130516-2joox.html

Liddy, N. (2102). Multicultural young people in Australia: Exploring structural barriers to education and employment. Mosaic, 32(summer), 6-8.

Lovatt, T., Mitchell, B., Nilan, P., Hosseini, S., Cook, B., Samarayi, I., \& Mansfield, M. (2011). Australian Muslim Jobseekers: Labour Market Experiences, Job Readiness, and the Relative Effectiveness of Employment Support Services. Australia: Department of Social Services. Retrieved from http://www. dss.gov.au/sites/default/files/documents/01_2014/ muslim-jobseekers.pdf

Markus, A. (2014). Recent Arrivals Report 2013. Mapping Social Cohesion. Caufield East: Monash University.

Masanauskas, J. (2012). High unemployment of among Muslims linked to war on terror. The Australian, 14 November 2012. Retrieved from http://www.thea ustralian.com.au/news/high-unemployment-among -muslims-linked-to-war-on-terror/story-e6frg6n6-1 226516162590

McLeod, J., \& Yates, L. (1999). Who is "us"? Students negotiating discourses of racism and national identification in Australia. Urban Policy and Research, 17(1), 29-49.

Meer, N., \& Modood, T. (2011). How does interculturalism contrast with multiculturalism? Journal of In- tercultural Studies, 33(2), 175-196.

Modood, T. (2012). Post-Immigration 'Difference' and Integration: The Case of Muslims in Western Europe. London: British Academy.

Montoya, D. (2012). Western Sydney: An economic profile. NSW Parliamentary Briefing Paper, 06/2012. Retrieved from https://www.parliament. nsw.gov.au/prod/parlment/publications.nsf/key/W esternSydney:AnEconomicProfile

Mumble Census Gallery. (2013). Election 2013 census table gallery. Retrieved from http://mumble.com. $\mathrm{au} / \mathrm{p} \mathrm{p}=2753$

Putnam, R. (Ed.) (2002). Democracies in Flux: The Evolution of Social Capital in Contemporary Society. New York: Oxford University Press.

Redmond, G., Wong, M., Bradbury, B., \& Katz, I. (2014). Intergenerational Mobility: New Evidence from the Longitudinal Surveys of Australian Youth. Canberra: NCVER.

Reynolds, T. (2006) Caribbean families, social capital and young people's diasporic identities. Ethnic and Racial Studies, 29(6), 1087-1103.

Refugee Council of Australia. (2011). Youth and Family Issues. Retrieved from http://www.refugeecouncil. org.au/f/smt-y\&f.php

Schaefer-McDaniel, N. J. (2004). Conceptualizing social capital among young people: Toward a new theory. Children, Youth and Environments, 14(1), 140-150.

Shah, B., Dwyer, C., \& Modood, T. (2010). Explaining educational achievement and career aspirations among young British Pakistanis: Mobilising "ethnic capital"? Sociology, 44(6), 1109-1127.

Tabar, P., Noble, G., \& Poynting, S. (2003). The rise and falter of the field of ethnic politics in Australia: The case of Lebanese community leadership. Journal of Intercultural Studies, 24(3), 267-287.

Wimmer, A. (2007). How (not) to think about ethnicity in immigrant societies: Toward a boundary making perspective. ESRC Centre on Migration, Policy and Society Working Paper No. 44. Oxford: University of Oxford. Retrieved from https://www.compas. ox.ac.uk/fileadmin/files/Publications/working_pape rs/WP_2007/WP0744-Wimmer.pdf

\section{About the Authors}

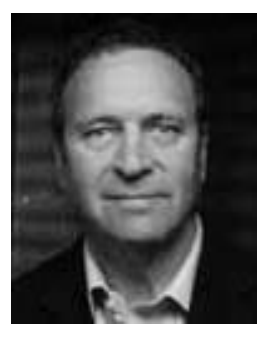

\section{Dr. Andrew Jakubowicz}

Dr. Andrew Jakubowicz is Professor of Sociology and co-director of the Cosmopolitan Civil Societies Research Centre at the University of Technology Sydney. He is a Board Member of the Institute for Cultural Diversity, an NGO dedicated to the advancement of cultural diversity leadership in Australia. His recent research includes a study on the background to African Immigration to Australia for the Human Rights Commission, on the influences on young Australian Muslims for the Australian Government, and on the human rights and wellbeing of international students for Universities Australia and the Academy of Social Sciences in Australia. 


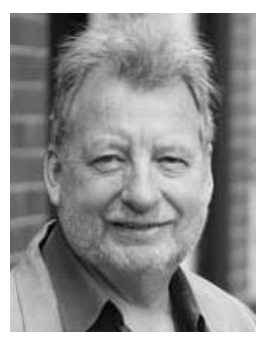

\section{Dr. Jock Collins}

Jock Collins is Professor of Social Economics in the Management Discipline Group at the UTS Business School, Sydney, Australia and Co-Director of the UTS Cosmopolitan Civil Societies Research Centre. His research relates to an interdisciplinary study of immigration and cultural diversity in the economy and society, including Australian immigration and multiculturalism, ethnic crime, immigrant and Indigenous entrepreneurship, immigrant youth, ethnic precincts and tourism, global teachers, immigrants and the built environment and immigrants in regional and rural Australia and the social use of ethnic heritage and the built environment.

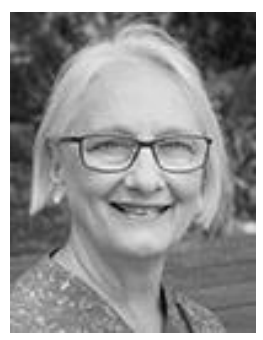

\section{Dr. Carol Reid}

Associate Professor Carol Reid is a sociologist of education in the Centre for Educational Research at the University of Western Sydney. Carol's research explores processes of globalisation and mobilities on youth, ethnicity and race and the intersections of these social identities with the changing nature of teacher's work. She is the International Sociological Association's the Sociology of Education Vice President for Oceania (2014-2018).

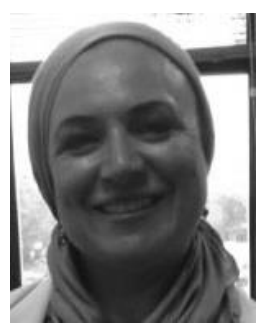

\section{Wafa Chafic}

Wafa Chafic is a counselling psychologist working in Western Sydney. She has an interest in migration and settlement processes, identity development, and resilience. Her research has focused on the social participation and capacity building approaches used by Australian Muslim young people and Muslim men of migrant, refugee and asylum seeker backgrounds. 